\title{
MODULATION OF THE INTRINSIC VISCOSITY OF HYALURONIC ACID FORMED BY HUMAN "FIBROBLASTS" IN VITRO: THE EFFECTS OF HYDROCORTISONE AND COLCHICINE
}

\author{
C. WILLIAM CASTOR AND ROBERT K. PRINCE \\ Department of Internal Medicine, The University of Michigan Medical School, \\ Ann Arbor, Mich. (U.S.A.) \\ (Received October 8th, 1963)
}

\section{SUMMARY}

Data are presented to show that the intrinsic viscosity of hyaluronic acid elaborated into the culture medium supporting human connective-tissue cells in vitro is modulated in a systematic manner by the cells. Intrinsic viscosity is reduced during rapid cell division and by hydrocortisone treatment. Conversely, the initial lag phase of culture growth and colchicine treatment are attended by formation of hyaluronic acid with a high intrinsic viscosity.

\section{INTRODUCTION}

Chemical analysis of connective tissue suggests that the various acid mucopolysaccharides are distributed in a tissue-specific pattern in different anatomic sites ${ }^{1}$. These anionic macromolecules are structural components of the connective-tissue ground substance, and, through their unusual properties they may influence metabolic events occurring in the intercellular milieu. Since many of the unique properties of these structural carbohydrates are related to molecular size itself, studies relevant to this physical parameter are appropriate.

The molecular weight of hyaluronic acid from mammalian tissues has been recorded at values ranging from $7.7 \cdot 10^{4}$ to $10 \cdot 10^{6}$ (refs. 2,3 ). Values differ depending on species, tissue source, method of sample preparation, and method of measuring molecular weight. In some tissues, as the bovine vitreous body, a spectrum of molecular weights has been demonstrated ${ }^{2}$. The precise nature of differences among tissues with respect to the molecular species of hyaluronic acid may eventually be delineated by systematic application of gentle isolation methods and sensitive biophysical measurement techniques. Implicit in these considerations is the concept that there are mechanisms for regulating the molecular dimensions of the hyaluronic acid found in connective-tissue ground substance.

This communication provides evidence that human connective-tissue cells, studied in vitro, are capable of varying the intrinsic viscosity of the hyaluronic acid which they form. Intrinsic viscosity has been measured as a parameter of the molecular weight of hyaluronic acid ${ }^{2}$. The present data suggest that the mean molecular weight 
of hyaluronate formed by human fibroblast cultures is inversely related to the rate of cell proliferation. In addition, the divergent effects of hydrocortisone and colchicine on the intrinsic viscosity of culture-produced hyaluronate are documented.

\section{METHODS}

\section{Preparation of connective-tissue cell cultures}

Human synovial tissue was excised from knee joints obtained at amputations and divided into fragments of I $\mathrm{mm} \times 2 \mathrm{~mm}$ for explantation under perforated cellophane in T-I5 flasks. Histologic study verified the normal morphology of the synovial membranes used in these studies. Cultures were developed and handled as reported earlier ${ }^{4,5}$. Culture medium was composed of $80 \%$ synthetic medium ro66 (Baltimore Biological Laboratory, Baltimore I8, Md.), Io \% heat-inactivated pooled human serum, and ro \% fetal calf serum. The medium was supplemented before use with L-glutamine and Ioo $\mu \mathrm{g}$ each of penicillin and streptomycin sulfate per $\mathrm{ml}$. Complete medium changes were carried out at 2 - to 3 -day intervals. When outgrowth of connective-tissue cells around explants was adequate, the flasks were incubated for I0-I5 min with $0.25 \%$ trypsin (EC 3.4.4.4) to liberate the cellular outgrowth from the glass into a uniform cell suspension. This suspension was centrifuged for $5 \mathrm{~min}$ at $65 \times \mathrm{g}$, the supernatant trypsin solution discarded, and the cells resuspended in fresh medium. Aliquots of the cell suspension were enumerated and sized with a Coulter Model B cell counter (Coulter Electronics, Hialeah, Fla.)

Stock cultures were inoculated by introducing approx. $I \cdot 10^{6}$ cells into $T-60$ flasks containing Io $\mathrm{ml}$ of medium. Harvesting and subculturing of the monolayer cultures was performed at 7 - to ro-day intervals. In addition to cell counts as an index of culture mass, total-culture protein measurements were carried out where appropriate by a modification ${ }^{6}$ of the method of Lowry. In some instances RNA and DNA were estimated on the basis of their respective pentoses in the supernatant portion of a ro $\%$ trichloroacetic acid extract of the cells?. This extraction was carried out at $90^{\circ}$ for $\mathrm{I} 5 \mathrm{~min}$.

\section{Viscosity measurements}

Measurements on whole medium: Ostwald viscosity pipettes with water flow times of 55-65 sec and a $3.0 \mathrm{ml}$ capacity were used for routine viscosity measurements. The relative viscosity of a specimen was defined as the ratio of its efflux time with polymerized hyaluronate to the efflux time following addition of testicular hyaluronidase $^{\star}$. All efflux times were determined three or more times and usually agreed within o.I sec. The relative viscosity of a whole medium specimen determined in this manner agreed closely with the value obtained by relating the flow time of a "used" medium specimen to the efflux time of an incubated "unused" medium specimen. To evaluate the anomalous viscosity of selected specimens, Fenske-Cannon viscometers with water flow times between ro and 200 sec were employed.

Measurements on hyaluronate isolated from culture medium: Semi-purified hyaluronate from culture medium (procedure described below) was dialyzed at $4^{\circ}$ for $4 \mathrm{~h}$

\footnotetext{
* I mg of hyaluronidase (300 USP units, Worthington Biochemical Corp., Freehold, N.J.) was added to the viscometer in $0.05 \mathrm{ml}$ of phosphate-saline buffer and incubated at $37^{\circ}$ until there was no further change in viscosity.
} 
or more against several changes of $0.05 \mathrm{M}$ phosphate buffer $(\mathrm{pH} 7.0)$, containing o.I5 $\mathrm{M} \mathrm{NaCl}$. After equilibration with the phosphate-saline buffer, relative viscosity measurements were performed with and without hyaluronidase as described for the whole medium.

The most highly purified hyaluronate samples were also equilibrated with the phosphate-saline buffer and the relative viscosity measured in the same manner. Thus, in several experiments intrinsic viscosity measurements were available in the original medium sample, at an intermediate stage in the isolation process, and in the final product.

As suggested by SUNDBLADT ${ }^{8}$, intrinsic viscosity was calculated from the following relation:

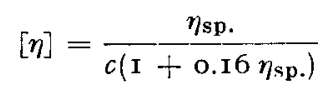

In this equation $c$ represents solute concentration in $\mathrm{g} / \mathrm{I}$ oo $\mathrm{ml}$, and $\eta_{\mathrm{sp}}=$ specific viscosity, (relative viscosity minus I). Where the specific viscosity is very low, the constant may be omitted without significantly impairing the validity of the expression.

\section{Chemical measurement of hyaluronate}

Measurement of hyaluronic acid concentration in the protein-rich culture medium was carried out by a modification of a method developed earlier in this laboratory ${ }^{9}$. The original method gave $85-100 \%$ recovery of purified hyaluronic acid added to culture medium and similar values for "native" hyaluronic acid in normal joint fluid, when the latter was added directly to culture medium. More recent studies have shown that the hyaluronic acid in pathologic joint fluid is often poorly recovered when the whole fluid is added to culture medium and measured by the original procedure. A step utilizing testicular hyaluronidase was introduced to decrease hyaluronate losses due to co-precipitation with protein during the heat step. This modification improved the recovery of hyaluronic acid from pathologic fluids that had been added to culture medium. Measurements of hyaluronic acid in medium removed from fibroblast cultures, using both the original method and the hyaluronidase modification, showed significantly higher values with the latter method. The original method appears to measure a consistent proportion (approx. $60 \%$ ) of the culture-produced hyaluronic acid, irrespective of cell strain, stage of cell growth or the presence of hormonal agents such as hydrocortisone. Earlier observations concerning the relative rate of mucopolysaccharide synthesis among different cell lines appear to be correct, due both to the proportional nature of the hyaluronate recovery and the wide spectrum of differences noted ${ }^{5}$. Using the original methed to determine medium hyaluronate, we had earlier shown that hydrocortisone depressed mucopolysaccharide synthesis by connective-tissue cells in vitro ${ }^{10}$. The steroid-suppression experiments were repeated and the hyaluronate determined by both the original and modified method. By both methods of measurement, data were obtained which indicated that I $\mu \mathrm{g}$ of hydrocortisone per $\mathrm{ml}$ of medium suppressed the rate of hyaluronate formation per unit of cell mass by approx. $50 \%$.

In the present study, the euglobulin-mucopolysaccharide complex was prepared by dialyzing the medium sample against $0.004 \mathrm{M}$ citrate-phosphate buffer ( $\mathrm{pH} 5.8$ ). This precipitate was centrifuged into a pellet which was incubated with $1.0 \mathrm{ml}$ of $0.05 \mathrm{M}$ acetate buffer ( $\mathrm{pH}$ 7.0), containing zoc USP units of testicular hyaluronidase. 
After 90 min incubation at $37^{\circ}, 2.0 \mathrm{ml}$ of $3.0 \mathrm{M}$ acetate buffer $(\mathrm{pH} 7.0$ ) was added and the heat precipitation step for protein removal carried out as with the previous procedure ${ }^{9}$. After centrifugation for Io $\min$ at $23500 \times g$, the supernatant solution may be analyzed for uronic acid by the carbazole method ${ }^{11}$.

Comparison of medium hyaluronate values measured by this method with those determined following isolation by proteolytic digestion indicates that recovery is nearly complete. In 28 samples so analyzed, the mean recovery of hyaluronic acid from culture medium by this modified procedure was $96 \pm 8 \%$.

\section{Isolation of hyahronic acid}

In order to study the physical properties of isolated hyaluronic acid, pooled specimens of 30.0-60.0 $\mathrm{ml}$ of culture medium were dialyzed for 3 days against $0.004 \mathrm{M}$ citrate-phosphate buffer ( $\mathrm{pH}_{5} .8$ ), with frequent changes of buffer. The euglobulinmucopolysaccharide complex was harvested by centrifugation at $14500 \times g$ in $50.0 \mathrm{ml}$ lustroid tubes. Io $\mathrm{ml}$ of $0.05 \mathrm{M}$ Tris buffer ( $\mathrm{pH} 8 . \mathrm{I}$ ) containing approx. $4.0 \mathrm{mg}$ of pronase* was added to each sample. A stirring bar was added to each tube and the incubation carried out with continuous stirring at $37^{\circ}$ over night. The resulting clear solution was designated "semi-purified" and equilibrated with phosphate-saline as noted earlier for viscosity measurement.

The final isolated product was prepared in a manner similar to that suggested by LAURENT et al. ${ }^{2}$. After stirred dialysis against water, the hyaluronate was quantitatively precipitated with $0.5 \mathrm{ml} 5.0 \%$ cetylpyridinium chloride, the precipitate collected by centrifugation and then dissolved in $5.0 \mathrm{ml}$ of $2.0 \mathrm{M} \mathrm{NaCl}$. This solution was then stirred for $2 \mathrm{~h}$ with I70.o $\mathrm{mg}$ Microcel $\mathrm{E}$ to remove protein and cetylpyridinium chloride. The $\mathrm{NaCl}$ concentration was reduced to $0.2 \mathrm{M}$ by dialysis against 9 volumes of distilled water and then the sodium salt of hyaluronic acid was precipitated by addition of 3 volumes of ethanol. The ethanol-precipitated hyaluronate was dissolved in phosphate-saline buffer for subsequent study.

\section{RESULTS}

\section{Intrinsic-viscosity changes in whole medium}

A monolayer culture of connective-tissue cells, designated "PK", was isolated from normal synovial tissue removed from the knee of an II-year old girl whose leg was amputated due to osteogenic sarcoma. On the fifth trypsin subculture, six replicate flasks were planted. During the first 2 days (first medium change), all flasks were treated alike, and then during the second and third medium changes one-half of the flasks received hydrocortisone at a medium concentration of $10 \mu \mathrm{g} / \mathrm{ml}$.

Control cultures grew well and formed hyaluronate in significant quantities (Table I). Of major interest was the observation that the relative viscosity of culture medium fell with each successive medium change. Since the relative-viscosity measurements are made with the control of hyaluronidase, the reduction in relative viscosity indicates either a declining quantity of hyaluronate, or a lesser degree of polymerization; or both. Inasmuch as hyaluronate concentration is also measured, the in-

* Pronase, a proteolytic enzyme formed by Streptomyces griseus obtained from California Corporation for Biochemical Research, Los Angeles, Calif. 


\section{TABLE I}

THE EFFECT OF GROWTH AND HYDROCORTISONE ON THE QUANTITY AND VISCOUS PROPERTIES OF HYALURONATE FORMED BY CONNECTIVE-TISSUE CELLS

Hydrocortisone hydrogen succinate was added to the "steroid" cultures only at the last two medium cha nges. HA refers to hyaluronic acid. $\eta_{\text {rel }}$. indicates the relative viscosity of the medium. (Note that relative viscosity decreases over the three time intervals despite minor variation, including increases, in the actual amount of hyaluronate formed by a given culture.) The rate calculation is made for the last 2 days of the culture growth cycle.

\begin{tabular}{|c|c|c|c|c|c|c|c|c|c|c|}
\hline \multirow{2}{*}{ Culture } & \multirow{2}{*}{$\begin{array}{c}\text { Hydro- } \\
\text { cortisone } \\
(\mu g / m l)\end{array}$} & \multirow{2}{*}{$\begin{array}{c}\text { Cell } \\
\text { count } \\
\left(\times 10^{6}\right)\end{array}$} & \multirow{2}{*}{$\begin{array}{c}\text { Cell } \\
\text { volume } \\
\left(\mu^{3}\right)\end{array}$} & \multicolumn{2}{|c|}{ Culture day $0-2$} & \multicolumn{2}{|c|}{ Culture day $2-5$} & \multicolumn{2}{|c|}{ Culture day $5^{-7}$} & \multirow{2}{*}{$\begin{array}{c}\text { Rate of } H A \\
\text { formation } \\
(\mu \mu \text { g/cell } \\
\text { per day })\end{array}$} \\
\hline & & & & $\begin{array}{c}\mu g H A \text { per } \\
\text { to } m l\end{array}$ & $\eta_{\text {rel }}$ & $\begin{array}{c}\mu g H A \text { per } \\
\text { Io ml }\end{array}$ & $\eta_{\text {rel. }}$ & $\begin{array}{l}\mu g H A \text { per } \\
\quad \text { ro } m l\end{array}$ & $\eta_{\text {rel. }}$ & \\
\hline PK-I 22-E & 0 & 5.177 & 4080 & 304 & I I I 30 & 3 I 3 & I.089 & 3 I 8 & $\mathrm{I} .066$ & 30.7 \\
\hline PK-I 23-E & o & $5.25 \mathrm{I}$ & 4080 & 267 & I. I I I & 297 & I. $.07 \mathrm{I}$ & 299 & 1.052 & 28.5 \\
\hline $\mathrm{PK}-\mathrm{I} 24-\mathrm{E}$ & o & 4.797 & 4182 & 273 & I. 124 & $34 I$ & I. Ogo & 303 & 1.058 & 31.6 \\
\hline PK-I 25-E & 10 & 6.493 & 2958 & 255 & I. I I 6 & 279 & 1.040 & 222 & 1.026 & 17.1 \\
\hline PK-I 26-E & IO & 6.123 & 2856 & $25 \mathrm{I}$ & I. I I 2 & 276 & I. .041 & $2 I_{4}$ & I.026 & I $7 \cdot 5$ \\
\hline PK-I 27-E & IO & 6.630 & $295^{8}$ & 275 & I . I I 4 & 277 & I. $04^{6}$ & 213 & I.030 & I 6.1 \\
\hline
\end{tabular}

trinsic viscosity of the medium hyaluronate, a measure of molecular weight, may be calculated. The decline in intrinsic viscosity of medium hyaluronate over the growth period of the culture is shown in Fig. I.

Flasks receiving hydrocortisone showed the anticipated acceleration of growth, reduction of cell volume, and suppression of hyaluronate synthesis ${ }^{10}$. It is evident from Table $I$ that the relative viscosity attributable to medium hyaluronate fell even more rapidly than did the total quantity of hyaluronate formed in the last two medium changes under the influence of hydrocortisone. Intrinsic viscosity (Fig. I) fell more rapidly than in control cultures, suggesting that hydrocortisone not only sup-

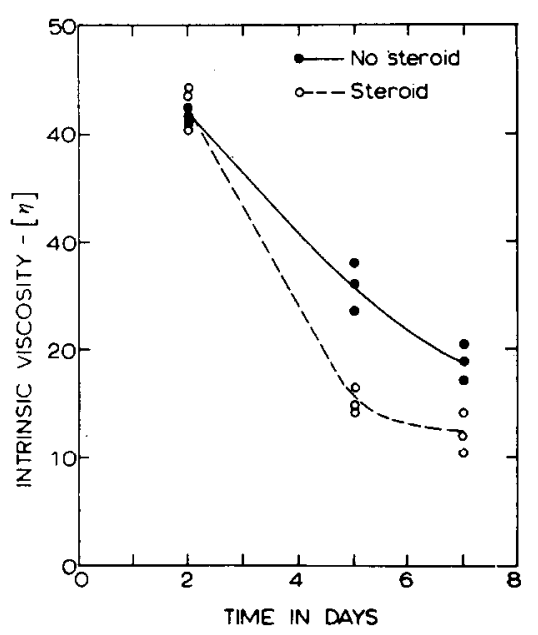

Fig. I. Three successive medium changes from "PK" cell strain show declining intrinsic viscosity as cultures grow. Flasks containing hydrocortisone for last two medium changes show an even greater fall in intrinsic viscosity.

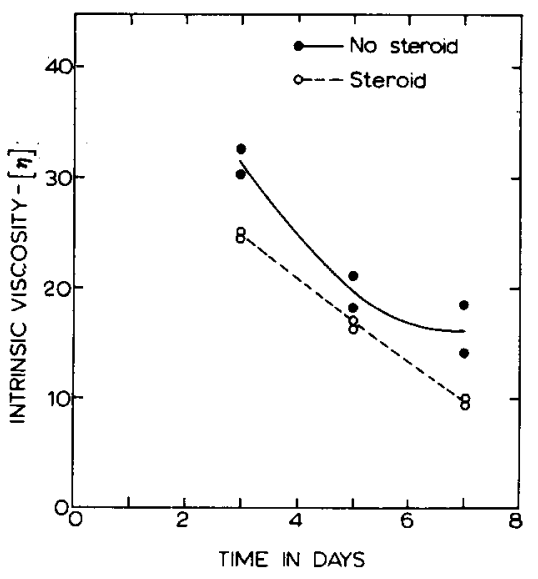

Fig. 2. Three successive medium changes from "WK" cell strain show declining intrinsic viscosity concurrent with culture growth. Steroidtreated flasks received hydrocortisone in each medium change, and all intrinsic-viscosity values fall below corresponding controls. 
presses the quantity of hyaluronate formed in this situation, but also negatively influences the degree of its polymerization.

To ascertain whether the intrinsic-viscosity modulation was peculiar to the " $\mathrm{PK}$ " cell line, a different line was developed and studied. Cell line "WK" was developed from the nornal synovial tissue of a $7 \mathrm{x}$-year old man who had an amputation due to peripheral vascular disease. Cells from the fourth trypsin subculture were planted and half of the flasks received r.o $\mu \mathrm{g}$ of hydrocortisone per $\mathrm{ml}$ throughout the experiment. In this second cell line, a lesser concentration of hydrocortisone induced a similar degree of growth acceleration, cell size reduction, and reduced the rate of hyaluronate formation from a mean control value of $65 \cdot \mathrm{IO}^{-12} \mathrm{~g} /$ cell per day to $25 \cdot \mathrm{IO}^{-12} \mathrm{~g} /$ cell per day. Relative viscosity due to medium hyaluronate again declined as the cultures grew, greater decrements being noted in the steroid-treated flasks. Intrinsic-viscosity calculations for medium hyaluronate during culture growth are plotted for each medium change (Fig. 2). In Fig. 2 it is noteworthy that both control and steroid cultures show the same pattern of diminishing intrinsic viscosity. Further, here where steroid cultures were exposed to the hormone throughout the experiment, all intrinsic viscosity values fell below their appropriate controls.

\section{Intrinsic-viscosity measurements on isolated hyaluronate}

Since all of the viscosity measurements described above were made on wholetissue culture medium containing $5{ }^{0-500} \mu \mathrm{g}$ of hyaluronate mixed with approx. $I_{50000} \mu \mathrm{g}$ of serum protein, it seemed prudent to attempt verification of the sequential changes in molecular size by studying hyaluronate isolated from the cultures.

The third experiment was made with the "PK" cell line when it had been cultivated in vitro for 3 months. Eight replicate cultures were planted and medium was changed on the second, fourth, seventh, and ninth days. Starting with the second medium change (added to flasks on second day of culture) half of the flasks received Io $\mu \mathrm{g}$ of hydrocortisone per $\mathrm{ml}$ of medium. Growth stimulation by hydrocortisone was not significant, but ceil size, medium viscosity. and medium hyaluronate all decreased. The specific rate of hyaluronic acid formation per cell was reduced $44.6 \%$ in the hydrocortisone-treated cultures.
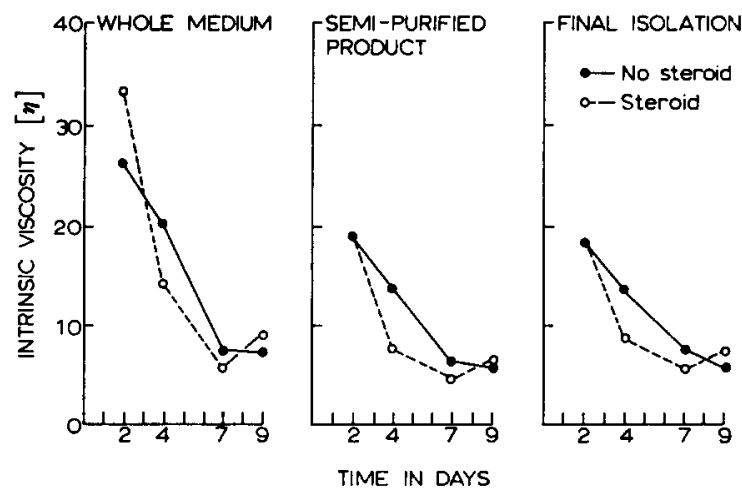

Fig. 3. Cell strain "PK" showed declining intrinsic viscosity over four successive medium changes. The sense of the change over the growth period was the same when isolated hyaluronate was studied. 
The intrinsic-viscosity data relevant to the hyaluronic acid in the whole medium, the semi-purified product and the final product are illustrated in Fig. 3. In contrast to the crude medium where mucopolysaccharide was a minor constituent, the semipurified products contained about $20 \%$ hyaluronate and the final products had $80-96 \%$ hyaluronate with small amounts of associated protein. It is apparent that the sense of the data based on the isolated products is in agrcement with the observations made on the crude medium with respect to the falling intrinsic viscosity during culture growth and the accentuation of this effect by hydrocortisone. It is also evident that the isolation procedure has inflicted at least an apparent loss of intrinsic viscosity, especially in those samples possessing the greatest intrinsic viscosity initially.

\section{The effect of colchicine}

Connective-tissue cells in control cultures synthesize hyaluronate possessing decreased intrinsic viscosity during that portion of the growth cycle associated with most rapid growth ${ }^{4}$. Further, hydrocortisone, which accelerates cell growth, tends to accentuate the diminution in this parameter of molecular weight. In an effort to influence cell-mediated alteration of intrinsic viscosity in a positive dirccti.n, the effect of agents which interfere with cell proliferation was explored.

Initial experiments with colchicine (Aqua Colchin, Parke Davis and Company, Detroit, Mich.) revealed that concentrations ranging from o.or $\mu \mathrm{g}$ to $\mathrm{I.O} \mu \mathrm{g}$ per $\mathrm{ml}$ of culture medium markedly inhibited mitosis, as judged by cell counts. Colchicinetreated cultures showed large, rounded cells which remained attached to glass. Cell volume was markedly increased and total culture protein was only slightly decreased
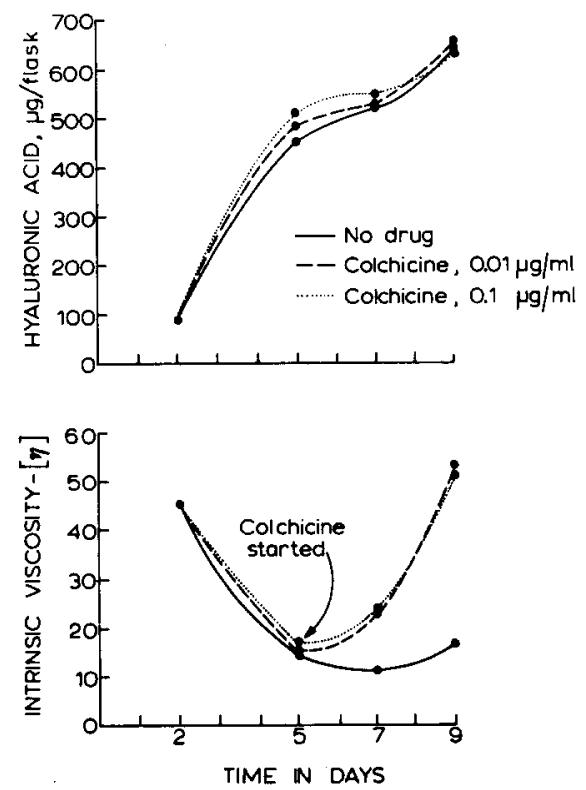

Fig. 4. The upper portion of the figure shows that colchicine-treated flasks differed little from control flasks with respect to the total amount of hyaluronate elaborated into the medium during various portions of the growth cycle. The lower panel of the figure demonstrates that the intrinsic viscosity of the medium rose over control values during the final 4 days when exposed to colchicine. 

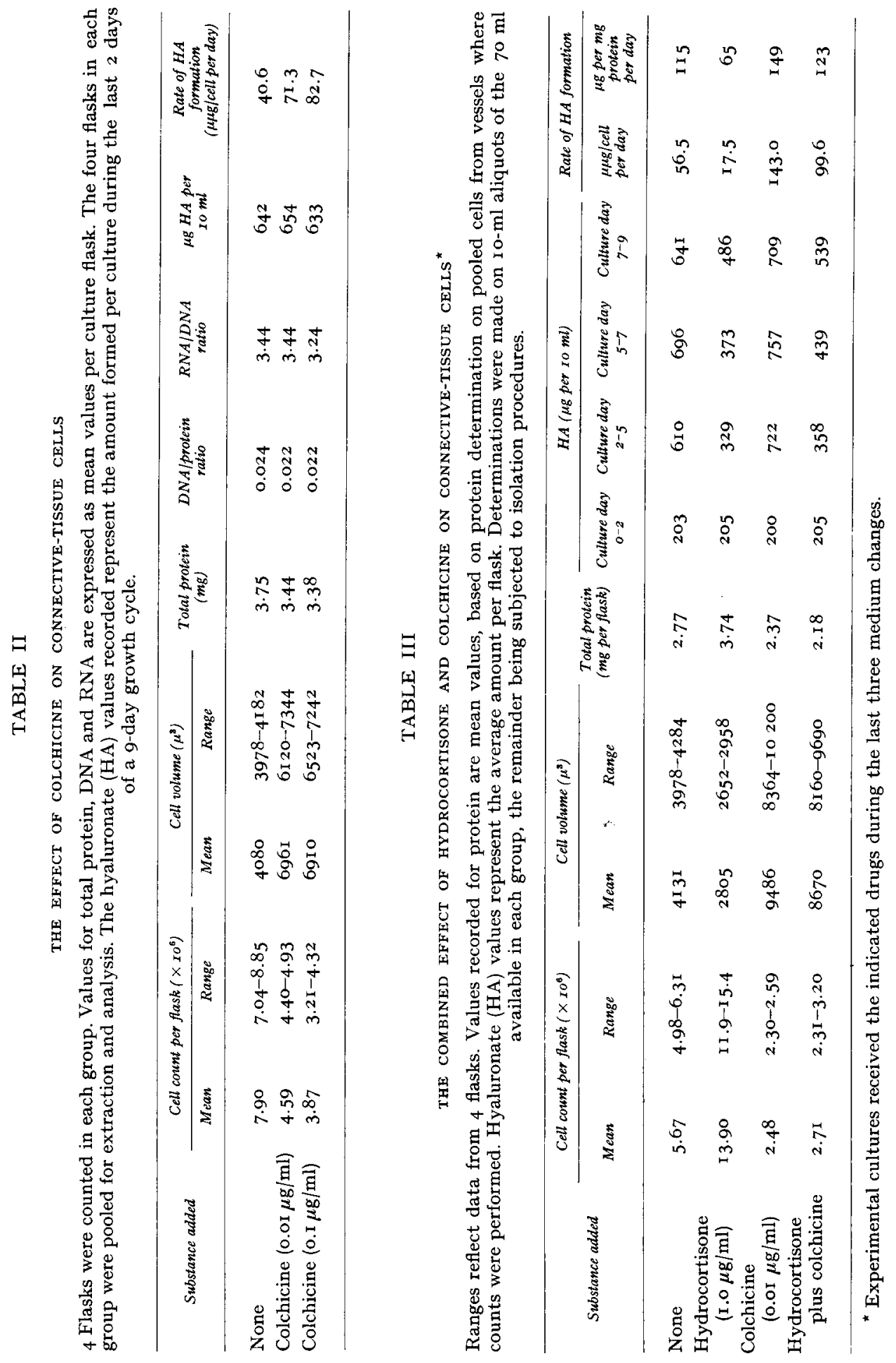

Biochim. Biophys. Acta, 83 (1964) I65-I 77 
in spite of lesser cell numbers. Of interest was the observation that the total amount of hyaluronic acid per flask was not reduced in those cultures treated with colchicine, even though the number of cells was drastically curtailed. Table II presents data from a typical experiment and shows similar effects imposed by two different concentrations of colchicine. The colchicine was added to experimental flasks for the last two medium changes, that is, days $5-7$, and days $7-9$. Inspection of the data suggests that control cell populations went through mitosis three times, while the third division was blocked in the colchicine-treated flasks. In spite of failure to go through the mitotic division, the experimental flasks had approximately the same total cell volume, total nucleic acid and protein content as the control flasks. The intrinsic viscosity of medium-hyaluronic acid promptly rose following addition of colchicine, as shown in Fig. 4 (lower portion). The absence of change in the total amount of hyaluronate formed is illustrated in the upper portion of the figure.

The final experiment described in this report was designed to (I) confirm the colchicine-induced elevation of intrinsic viscosity by studying isolated hyaluronate and (2) evaluate the effect of hydrocortisone and colchicine used together. 28 flasks of "PK" articular connective-tissue cells were divided into the four groups indicated in Table III.

Experimental flasks received the hormone and anti-mitotic agent starting with the second medium change. It is apparent in Table III that hydrocortisone stimulated growth, as measured by cell numbers and total culture protein, and reduced cell volume. The total quantity of hyaluronate formed was promptly reduced, and the rate of formation per unit of cellular material, calculated either for the individual cell or per unit of cellular protein, was also markedly depressed. Colchicine, however, suppressed total cell numbers while permitting the individual cells to enlarge and form almost as much protein as control cultures. The total hyaluronate per culture flasks was modestly increased over control flasks. Calculation of the rate of hyaluronate formation during the last 2 days of the culture cycle suggests that there was a profound increase in the amount of mucopolysaccharide formed by each cell. However, if one corrects for the increased size and protein content of colchicine-treated cells and

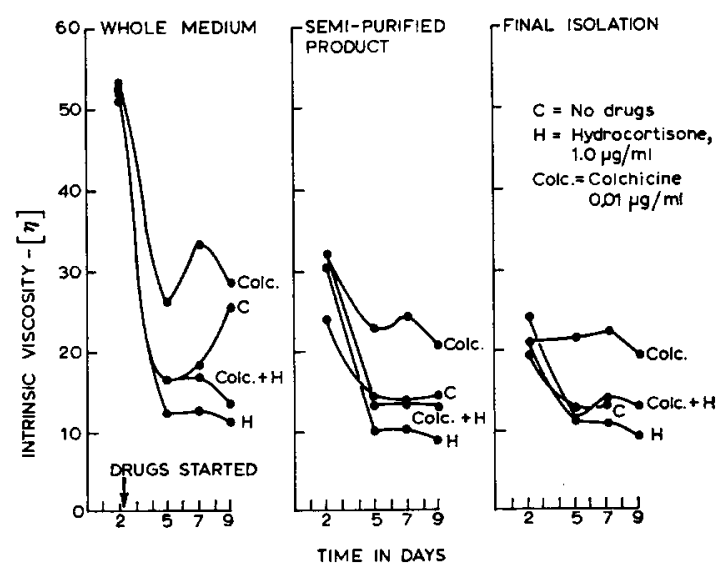

Fig. 5. The colchicine-induced elevation of intrinsic viscosity is demonstrable in relatively proteinfree preparations. 
calculates the rate per unit of culture protein, the "stimulation" of the rate of hyaluronate synthesis assumes more modest proportions.

In the cultures exposed to both hydrocortisone and colchicine, the anti-mitotic activity of the latter dominated under the conditions of this experiment. Of great interest, however, is the quantitative depression of hyaluronic acid in all media from cells exposed to these agents in combination. The amount of hyaluronate formed lies between control values and the markedly depressed values resulting from hydrocortisone alone. Calculations of the rate of hyaluronate synthesis, shows values above control cultures, but less than with colchicine alone. It follows that hydrocortisone suppression of mucopolysaccharide synthesis in cultures does not require steroidinduced growth acceleration and thus is separable from this latter effect.

Intrinsic-viscosity data for this experiment is plotted in Fig. 5. It is apparent that colchicine alone induced a higher intrinsic viscosity than in control cultures, whether compared in the original medium or in the isolated products. As in other experiments, the hydrocortisone-treated cultures yielded hyaluronate of inferior intrinsic viscosity. When the two agents were used together, the colchicine type of effect was clearly suppressed, although the low intrinsic viscosities associated with hydrocortisone alone were not achieved.

\section{Characteristics of culture-produced hyaluronic acid}

Associated protein: During the last experiment described above, $\mathbf{r} 6$ specimens of hyaluronate of varying intrinsic viscosity were isolated. Protein "contamination" averaged $6 \%$ with values ranging from $3.6 \%$ to $9.4 \%$. Even though these minor amounts of protein remain associated with hyaluronic acid following digestion by a potent proteolytic enzyme and subsequent fractionation with cetylpyridinium and Microcel E, it is by no means certain that the protein moiety was specifically "built in" by the synovial cell.

Anomalous viscosity: To determine the magnitude of shear-dependent flow anomalies in solutions of culture-produced hyaluronate, representative samples were studied in Fenske-Cannon viscometers with widely varying flow times. The tangential stress at the capillary wall $(\tau)$ was calculated for each viscometer using the following relation:

$$
\tau=\frac{P r}{2 l}
$$

The mean hydrostatic pressure $(P)$ is expressed in dynes $/ \mathrm{cm}^{2}, l$ refers to the length of the capillary tube and $r$ to its radius. Following the measurement of flow times for the different preparations, the viscosity was calculated from the following equation:

$$
\eta=\rho A t-\frac{\rho B}{t}
$$

In this expression, $\rho$ represents the density of the sample, $t$ refers to the observed flow time, and $A$ and $B$ are constants calculated separately for each viscometer. The constant $B$ was calculated from the geometry of the viscometer and $A$ was calculated after measuring the flow times of materials of known density and viscosity. When solutions of "isolated hyaluronate" with intrinsic viscosities ranging from 9.6 to 22.8 were examined, it was found that increasing stress did not materially alter the 
specific viscosity. Since hyaluronic acid of very high intrinsic viscosity tended to be degraded by isolation procedures, this material was studied in the whole medium. The initial medium change from a culture of "WK" fibroblasts had II.4 $\mu \mathrm{g}$ of hyaluronic acid per $\mathrm{ml}$ of medium, and its intrinsic viscosity was estimated at 44.7 . The flow time of this medium was measured in viscometers whose tangential stress at the capillary wall varied from I5.I dynes $/ \mathrm{cm}^{2}$ to $37 . \mathrm{I}$ dynes $/ \mathrm{cm}^{2}$. Essentially no stress-related change in specific viscosity could be demonstrated, probably due to the marked dilution of the hyaluronic acid. Hence, the intrinsic-viscosity measurements recorded for hyaluronic acid may be regarded as reasonably free of error due to shear-dependent anomalous flow.

\section{DISCUSSION}

Viscometry has been used by others to identify hyaluronic acid in the supernatant medium from cultures of articular and periarticular connective-tissue cells ${ }^{12,13}$. In more recent studies HEDBERG AND MORITZ ${ }^{14}$ measured the intrinsic viscosity of medium from primary explant cultures, some of which were cultivated in the presence of serum from patients with rheumatoid arthritis. These studies were interpreted as showing no appreciable influence of rheumatoid sera on the intrinsic viscosity of the hyaluronate formed by the cultures. Measurements of intrinsic viscosity were made at weekly intervals and sometimes showed a tendency to decrease as the culture aged, leading the authors to speculate about the possibility of cell selection within the cultures.

In the present investigation, monolayer cultures of human fibroblasts, nourished by a semisynthetic medium, were studied under conditions permitting measurement of several parameters of culture growth as well as detailed scrutiny of hyaluronate synthesis by the proliferating cells.

In the cell strains described in this report, the intrinsic viscosity of medium hyaluronate always fell markedly from the high values noted in the initial medium changes. When a culture was full grown and filled the floor of the flask, the hyaluronic acid formed had a modest or low intrinsic viscosity. Division of such a "mature" culture into daughter subcultures promptly led to the formation of hyaluronic acid of high intrinsic viscosity. These daughter subcultures in turn exhibited declining intrinsic viscosity values over their period of rapid growth. This "see-saw" process has continued for more than 5 months in vitro, and as yet these cell strains show no significant loss of ability to form highly polymerized hyaluronic acid during the early stages of the growth cycle. One change which may be related to the increasing age of the cell strain deserves comment. Cell strain "PK" during its early weeks in vitro formed hyaluronic acid of high intrinsic viscosity not only during the lag phase of growth, but at the end of the growth cycle (resting phase) as well. After the cell strain had been in vitro for several months this secondary increase in intrinsic viscosity was replaced by a plateau.

LAURENT and co-workers demonstrated that hyaluronate isolated from bovine vitreous body had properties which could be described by the following equation:

$$
[\eta]=0.036 M^{0.78}
$$

If one assumes that this expression in equally valid for the material which we have studied, it is possible to calculate the molecular weight $(M)$ of the hyaluronic acid 
found at various stages of the growth cycle. Intrinsic viscosities of 40,20 , and Io correspond to molecular weights of $2.9 \cdot 10^{6}, 1.2 \cdot 10^{6}$, and $5.0 \cdot 10^{5}$ respectively. Reference to the text figures suggests that the molecular weight of hyaluronic acid falls to onehalf to one-fifth its initial value over the course of the growth cycle. Such an extrapolation from intrinsic viscosity to molecular weight assumes that the cell forms a flexible straight-chain polymer, and that increasing degrees of cross linking or chain branching do not occur during culture growth.

The mechanism by which a connective-tissue cell modulates the size of its extracellular product is not known. The data indicates that the hyaluronic acid found in the medium has a variable molecular weight related to the status and condition of the culture. Whether there is variation in the molecular weight of the polymer at the time of synthesis or whether the data reflect the fluctuating activity of degradative substances, (hyaluronidases, reducing substances) can not be stated with certainty. However, to postulate a hyaluronidase effect would require an extremely low level of enzyme activity over a $48-72-\mathrm{h}$ incubation period at $37^{\circ}$ in order to account for the sizable residual polymers which are actually observed. Moreover, to postulate that decreased polymer size is related to the action of reducing substances ignores the fact that cysteine and ascorbic acid are present in high concentration in each medium change, including those showing a high intrinsic viscosity. In this connection it is relevant that incubation at $37^{\circ}$ for $24 \mathrm{~h}$ did not significantly reduce the viscosity of medium removed from cell cultures. Furthermore, incubation of late growth-cycle media with highly-purified viscous hyaluronate, $\left(5 \mathrm{~h}\right.$ at $\left.37^{\circ}\right)$ did not reduce the viscosity of the mixture. Hence we have no evidence favoring degradative substances free in the culture medium.

The experiments with hydrocortisone show that this agent has a negative effect on the polymer size of hyaluronic acid formed by human connective-tissue cells in vitro, and they extend previous data demonstrating suppression of the rate of formation of hyaluronic acid by such cells ${ }^{10}$. Although quantitative suppression of hyaluronate formation by hydrocortisone is usually associated with accelerated growth, these effects can be separated, as illustrated by the experiment in which cultures were exposed to both hydrocortisone and colchicine.

The dramatic rise in intrinsic viscosity of culture-produced hyaluronic acid following treatment with colchicine is not easily explained. It would be convenient to equate the circumstances where cells are not dividing, (lag phase, colchicine treatment) with the capacity for producing a large polymer. Conversely, where cells are rapidly dividing, (log phase, hydrocortisone effect), it might be argued that circumstances were in some way less favorable for the synthesis, or preservation, of large polymers. An equally valid interpretation of the data should, however, be pointed out. Both the trypsin-dispersion process and the colchicine exposure may represent non-specific injury leading to a stereotyped cellular reaction to injury, that is : formation of a larger hyaluronic acid polymer.

\section{ACKNOWLEDGEMENTS}

It is a pleasure to acknowledge the assistance provided by Dr. J. L. ONCLEY, Professor of Biochemistry, University of Michigan Medical School and Director of Biophysics Research Division, Institute of Science and Technology, University of Michigan, Ann Arbor, Mich. 
One of the authors (C. W.C.) is a Career Research Development Awardee, United States Public Health Service.

This study was supported by United States Public Health Service Grant A-3665.

\section{REFERENCES}

1 K. Meyer, E. Davidson, A. Linker and P. Hoffman, Biochim. Biophys. Acta, 2 I (I956) 506.

2 T. C. Laurent, M. Ryan and A. Pietruszkiewicz, Biochim. Biophys. Acta, 42 (1960) 476.

3 J. H. Fessler, Biochem. $J$., 76 (1960) 124.

4 C. W. Castor and F. F. Fries, J. Lab. Clin. Med., 57 (I96I) 394.

3 C. W. Castor, R. K. Prince and E. L. Dorstewitz, Lab. Invest., i i (I962) 703.

6 V. I. Oyama and H. Eagle, Proc. Soc. Exptl. Biol. Med., 9 I (I956) 305.

7 E. Volkin and W. E. Cohn, Methods Biochem. Anal., I (1954) 287.

${ }^{8}$ L. Sundblad, Acta Soc. Med. Upsalien., $5^{8}$ (1953) II3.

- R. K. Prince and C. W. Castor, Exptl. Cel Res., 23 (I96I) 6I8.

${ }^{10}$ C. W. Castor, J. Lab. Clin. Med., 60 (I962) 788.

11 Z. Dische, J. Biol. Chem., I67 (I947) I89.

12 D. H. King, M. G. Levine and S. Weiss, Proc. Soc. Exptl. Biol. Med., 89 (1955) 261.

13 H. Hedberg and U. Moritz, Proc. Soc. Exptl. Biol. Med., 98 (1958) 80.

14 H. Hedberg and U. Moritz, Acta Rheumatol. Scand., 5 (I959) I69. 